\title{
Levetiracetam as an alternative therapy for Tourette syndrome
}

This article was published in the following Dove Press journal:

Neuropsychiatric Disease and Treatment

25 May 2010

Number of times this article has been viewed

\section{MA Martínez-Granero \\ A García-Pérez \\ F Montañes \\ Department of Pediatrics and Psychiatry, Hospital Universitario Fundación Alcorcón, Madrid, Spain}

Correspondence: Miguel A Martínez-Granero

Department of Pediatrics, Hospital Universitario Fundación Alcorcón, C/Budapest I. Alcorcón 28922, Madrid, Spain

Email mamartinezg@fhalcorcon.es

\begin{abstract}
Tourette syndrome is a common childhood-onset neuropsychiatric disorder characterized by chronic tics and frequent comorbid conditions such as attention deficit disorder. Most currently used tic-suppressing drugs are frequently associated with serious adverse events. Thus, alternative therapeutic agents with more favorable side-effect profiles are being evaluated. New hypotheses and recent studies involving GABAergic system in the pathophysiology of Tourette syndrome suppose a reason for the evaluation of GABAergic drugs. Levetiracetam is a drug with an atypical GABAergic mechanism of action that might be expected to improve tics. Although trials performed to evaluate the efficacy of levetiracetam in the treatment of Tourette syndrome have provided conflicting results, it may be useful in some patients. The established safe profile of levetiracetam makes this drug an alternative for treatment if intolerance to currently used drugs appears, but additional evaluation with larger and longer duration controlled studies are necessary to assess the real efficacy in patients with Tourette syndrome.
\end{abstract}

Keywords: Tourette syndrome, levetiracetam, tics, children, adolescents, GABA

\section{Tourette syndrome: Introduction}

Tourette syndrome (TS) is a childhood-onset neuropsychiatric disorder characterized by multiple chronic motor and vocal tics with a waxing and waning, fluctuating course. TS is a common disorder, with a prevalence of $1 \%-3 \%$ in school-age children and $0.5 \%$ in adolescents. ${ }^{1,2}$

In the majority of patients with TS, tics are associated with other disturbances such as attention deficit hyperactivity disorder (ADHD), obsessive-compulsive disorder (OCD), learning difficulties, emotional problems, mood and anxiety symptoms, oppositional defiant disorder, and other disruptive behaviors. These comorbidities complicate the outcome of the condition, with negative effects on peer acceptance, self-esteem and academic performance. , $^{3,4}$

\section{Pathogenesis of Tourette syndrome}

The findings from the preceding studies support the notion that TS is a complex genetic disorder of synaptic neurotransmission that involves basal ganglia and frontocortical circuits. Anatomical and functional neuroimaging studies have shown abnormalities in prefrontal cortical, paralimbic and striatal regions of the brain. Abnormal activity in the cortico-striato-thalamo-cortical pathways are involved in TS and its accompanying neuropsychiatric comorbidities. ${ }^{5-8}$ 
Several neurotransmitters are involved in these pathways, although it is widely believed that abnormalities of dopamine neurotransmission play a primary role in the physiopathology of TS. This hypothesis arises, in part, from evidence from pharmacological trials of therapeutic response to blockade of dopamine receptors, several functional imaging studies, and post-mortem studies. ${ }^{9-11}$ However, in spite of the evidence implicating dopaminergic dysfunction in TS, other neuropathologic and functional imaging studies have demonstrated contradictory findings. ${ }^{10}$

Therefore, the precise neurobiologic abnormality remains undefined. Other different neurotransmitters within the cortico-striato-thalamo-cortical circuits may also be involved in physiopathology of TS. ${ }^{7}$

\section{Classical treatments in Tourette syndrome}

Although tics tend to fluctuate within short periods of time, and improve or resolve over time, especially after puberty, tics can impair the quality of life of children and adolescents by interfering with social interactions, school performance, and activities of daily living. ${ }^{12,13}$

For patients with mild symptoms, educational and psychological interventions may be sufficient. Drug therapy should be considered for patients whose symptoms interfere with their quality of life.

Treatment of tics in TS is symptomatic. The goals of treatment should be to reduce the severity, frequency, and disruptive impact of symptoms, to manage associated psychiatric and learning problems, and to improve social functioning. ${ }^{13}$

The presence of comorbidities can complicate the treatment of patients with TS. Therapy must be individualized, and the most troublesome symptoms should be targeted first. Treatment of comorbid behavioral symptoms usually exerts a significant beneficial effect on tics. In other patients, a reduction in tics might improve self-esteem, which in turn results in improved behavior and school performance.

There is no ideal anti-tic pharmacotherapy. Drugs have highly variable results and, unfortunately, are often associated with side-effects. ${ }^{6,13-16}$ The most widely used treatments have consisted of neuroleptics and alpha-2 adrenergic agents.

Dopamine receptor-blocking drugs (neuroleptics) are considered the most effective tic-suppresing agents. Classical or typical neuroleptics have shown great efficacy in controlled clinical trials, ${ }^{17,18}$ but frequent side-effects often limit their usefulness. ${ }^{6,19}$

Alpha-2 adrenergic agents (clonidine and guanfacine) are better tolerated but may be not as effective as neuroleptics.
They are a good alternative for patients with tics and ADHD, because both conditions may respond..$^{20,21}$

The atypical neuroleptics risperidone ${ }^{22-24}$ and olanzapine $^{25,26}$ showed efficacy in randomized, controlled trials. Although associated with fewer side-effects than typical neuroleptics, these are still frequent, ${ }^{6,16}$ and children may be more vulnerable than adults. ${ }^{27}$ Attention must be paid to sedation, weight gain, extrapyramidal reactions, electrocardiographic alterations, and development of the metabolic syndrome (obesity, dyslipidemia, hypertension, and impaired glucose metabolism). ${ }^{28,29}$

Because of frequent side-effects, multiple non-neuroleptic alternative medications and non-pharmacological treatments have been evaluated for the treatment of tics. ${ }^{6,9,12,30}$

\section{Implication of gamma-aminobutyric acid (GABA) in Tourette syndrome}

The pathophysiology of TS is not fully understood, but basal ganglia dysfunction involving GABAergic neurons is one proposed cause of tics. ${ }^{10}$

Aberrant development of GABAergic circuits has been implicated in TS. In one study, marked alteration in the distribution of GABAergic neurons was found through neuropathological examination of basal ganglia tissue from TS patients. A decreased number and density of GABAergic interneurons in the striatum and external segment globus pallidus, as well as an increase in the number and proportion of GABAergic projection neurons of the internal segment of the globus pallidus were found. The authors speculated that these alterations would be consistent with a developmental defect in tangential migration of some GABAergic neurons. ${ }^{31}$

Many inhibitory GABAergic interneurons of the cerebral cortex migrate tangentially from the same embryogenic regions in the ganglionic eminence that also give rise to the GABAergic projecting neurons of the striatum. ${ }^{32}$ One hypothesis is that an adverse event at a specific developmental point could impair the appropriate migration and maturation of these cells and their assembly into inhibitory motor-control circuits. ${ }^{6}$

It is not completely understood how alterations in GABAergic interneurons and globus pallidus projection neurons could lead to a tic disorder. It has been hypothesized that in TS, a decrease in striatal GABAergic projections would cause insufficient inhibition of excitatory thalamocortical neurons, with the ultimate result being increased glutamatergic cortical excitation and the appearance of tics. ${ }^{6}$

Most TS patients over the age of 10 years report premonitory sensations preceding motor or vocal tics, 
and an irresistible urge to perform the tic. ${ }^{33}$ This probably reflects a failure in motor inhibition because of diminished ability to appropriately manage sensory inputs. ${ }^{34}$ Comorbid behavioral conditions such as OCD, ADHD, impulse control disorder, and intermittent explosive disorder are also related to impaired inhibition of inappropriate behaviours. Studies with transcranial magnetic stimulation have shown that the cortical silent period (period of decreased excitability following stimulation) is significantly shortened, and the intracortical inhibition is defective in TS patients compared to controls. ${ }^{35}$ This intracortical excitability is also seen frequently in children with ADHD comorbid with a tic disorder. Because motor cortex lesions are unlikely in TS patients, abnormal intracortical inhibition must be the consequence of a dysfunction of the subcortical input.

If these alterations in GABAergic system play a role in the pathophysiology of TS, then GABAergic drugs might be expected to improve tics. Thus, GABAergic drugs such as clonazepam, baclofen, and topiramate have been evaluated in treatment of tics, with varying results.

Only a modest tic-suppressing effect has been reported with clonazepam in the published case series. ${ }^{14}$

The GABA-B agonist baclofen has been effective in improving tics in one open-label trial, without baseline or follow-up scores. ${ }^{36}$ In a small, double-blind, placebocontrolled, crossover study, baclofen had benefit over placebo, although the beneficial response was associated with improvement in impairment scores rather than with a reduction of motor or vocal tics. ${ }^{37}$

In a randomized, double-blind, placebo-controlled trial, topiramate produced a statistically significant improvement in TS patients with moderate to severe symptoms..$^{38}$

\section{Levetiracetam}

Levetiracetam (LEV) is a broad-spectrum antiepileptic agent that has been used effectively for a variety of seizure types in adults and children, and for different psychiatric disorders. ${ }^{39,40}$

LEV does not have a direct effect on GABA receptormediated responses. In vitro findings reveal that LEV behaves as a modulator of GABA type $\mathrm{A}$ and of the glycine receptors, suppressing the inhibitory effect of other negative modulators (beta-carbolines and zinc). LEV inhibits the ability of zinc and beta-carbolines to interrupt chloride influx, an effect that enhances chloride ion influx at the GABA type A receptor complex. ${ }^{41,42}$

A brain-specific binding site for LEV was demonstrated for the first time in the brain tissue of rats. ${ }^{43}$ No specific binding was observed in peripheral tissues. More recently, this binding site has been identified as the SV2A protein, a protein ubiquitously distributed in the central nervous system as a component of synaptic vesicles. ${ }^{44}$ The binding of LEV is reversible, saturable, and highly selective to this protein.

SV2A is required for normal neurotransmission. In the absence of this protein, action potential-dependent GABAergic neurotransmission is reduced. The exact role of the SV2A protein is not fully understood, but it is thought to be involved in the regulation of vesicle exocytosis. ${ }^{45}$

The most frequently reported adverse events with LEV include somnolence, irritability, asthenia, headache, dizziness, and flu syndrome and are usually mild. In clinical trials, the incidence of adverse effects leading to dosage reduction or discontinuation was similar to placebo ( $15 \%$ vs $11.6 \%)^{39,40}$ In a systematic review of adults receiving LEV in long-term clinical trials, LEV had a relatively low incidence $(13 \%-16 \%)$ of adverse psychiatric and behavioral events; apathy, emotional lability, agitation, anxiety, depression, anger, hostility, personality changes, and suicidal ideation are reported events. ${ }^{46}$ Reversible psychosis associated with LEV therapy was observed in children and adolescents. ${ }^{47}$ These adverse behavioral symptoms are more common in patients with epilepsy or a previous history of behavioral or psychiatric problems, and can be the primary reason for discontinuation of the medication. ${ }^{39,40,47}$ Adverse behavioral events did not appear to be dose-related. Most of the behavioral problems associated with LEV therapy resolved within days after discontinuation of medication, and were not associated with any long-term disability.

The metabolism of levetiracetam is independent of the cytochrome P450 system. The absence of hepatic metabolism is associated with a very low potential for drug interactions and levetiracetam has no known clinically significant interactions. ${ }^{39}$

\section{Trials with levetiracetam in Tourette syndrome}

Due to its GABAergic mechanism of action, LEV could produce a beneficial effect in patients with TS. Several studies, discussed below, were conducted to investigate the effectiveness of LEV for the treatment of tics in children and adolescents with TS (Table 1).

The most widely-used instruments for measuring tic severity in therapeutic trials are the Yale Global Tic Severity Scale (YGTSS) and Clinical Global Impression (CGI) scale.

The YGTSS consists of a rating of severity for motor and vocal tics separately, with a scale of 0 to 5 for each tic's 
Table I Studies with Levetiracetam in Tourette syndrome patients

\begin{tabular}{|c|c|c|c|c|c|}
\hline Ref & Study type & Subjects & Intervention & Outcomes & Remarks and limitations \\
\hline 49 & $\begin{array}{l}\text { Prospective, } \\
\text { opel-label }\end{array}$ & $\begin{array}{l}60 \text { patients } \\
(<18 \text { yrs })\end{array}$ & LEV I-2 g/day & $\begin{array}{l}100 \% \text { improvement of tics } \\
43 / 60 \text { improved in behavior and } \\
\text { school performance }\end{array}$ & $\begin{array}{l}\text { Open-label design } \\
\text { Discontinuation in } 3 \text { patients } \\
\text { because exacerbation of previous } \\
\text { behavioral or ADHD symptoms. }\end{array}$ \\
\hline $\begin{array}{l}49 \\
50\end{array}$ & $\begin{array}{l}\text { Prospective, open- } \\
\text { label, 4-years } \\
\text { follow-up }\end{array}$ & $\begin{array}{l}60 \text { patients }+10 \\
\text { additional patients } \\
(6-18 \mathrm{yrs})\end{array}$ & LEV I-2 g/day & $\begin{array}{l}100 \% \text { improvement of tics } \\
70 \% \text { improvement in behavior and } \\
\text { school performance }\end{array}$ & $\begin{array}{l}\text { Open-label study design } \\
\text { Long follow-up }\end{array}$ \\
\hline 51 & $\begin{array}{l}\text { Randomized, } \\
\text { placebo- } \\
\text { controlled, } \\
\text { double-blind, } \\
\text { crossover study }\end{array}$ & $\begin{array}{l}22 \text { patients } \\
(8-16 \text { yrs })\end{array}$ & $\begin{array}{l}\text { LEV }(750-3000 \\
\mathrm{mg} / \text { day or } 30 \\
\mathrm{mg} / \mathrm{kg} / \text { day } \mathrm{max}) \\
\text { or placebo in } \\
\text { randomized } \\
\text { sequence } 4 \text { weeks } \\
\text { each }\end{array}$ & $\begin{array}{l}\text { Slight reduction in tics with no } \\
\text { significant differences between } \\
\text { groups } \\
\text { No improvement in ADHD } \\
\text { or obsessive-compulsive behaviors }\end{array}$ & $\begin{array}{l}\text { Short duration of treatment phase } \\
\text { ( } 4 \text { weeks) }\end{array}$ \\
\hline 52 & $\begin{array}{l}\text { Randomized, } \\
\text { double-blind, } \\
\text { crossover study }\end{array}$ & $\begin{array}{l}\text { I2 patients } \\
\text { (8-27 yrs) }\end{array}$ & $\begin{array}{l}\text { LEV }(250-1750 \\
\mathrm{mg} / \text { day or max } 50 \\
\mathrm{mg} / \mathrm{kg} / \text { day }) \text { or clonidine } \\
(0.15-0.3 \mathrm{mg} / \text { day }) \\
\text { in randomized } \\
\text { sequence } 6 \text { weeks } \\
\text { each }\end{array}$ & $\begin{array}{l}\text { Slight reduction in tics with } \\
\text { clonidine. No improvement with } \\
\text { LEV in tics, ADHD or OCD }\end{array}$ & $\begin{array}{l}\text { Reduced number of patients } \\
\text { Under-representation of patients } \\
\text { with comorbidities }\end{array}$ \\
\hline 53 & $\begin{array}{l}\text { Prospective, } \\
\text { opel-label }\end{array}$ & $\begin{array}{l}29 \text { patients } \\
(6-17 \mathrm{yrs})\end{array}$ & $\begin{array}{l}\mathrm{LEV}(30-40 \\
\mathrm{mg} / \mathrm{kg} / \text { day or } \\
\max 2 \mathrm{~g} / \text { day }) \\
12 \text { weeks } \\
\text { treatment }\end{array}$ & $\begin{array}{l}59 \% \text { improvement in tics. } 26 \% \text { no } \\
\text { changes. } 15 \% \text { worsened } \\
\text { Significant improvement in tics in } \\
\text { ADHD-associated subgroup }\end{array}$ & $\begin{array}{l}\text { Simultaneous treatment with } \\
\text { methylphenidate } \\
\text { Discontinuation in II\% } \\
\text { because of adverse effects }\end{array}$ \\
\hline 54 & $\begin{array}{l}\text { Randomized, } \\
\text { placebo- } \\
\text { controlled, } \\
\text { double-blind }\end{array}$ & $\begin{array}{l}24 \text { patients } \\
\text { (6-18 yrs) with } \\
\text { associated epilepsy } \\
\text { or headache }\end{array}$ & $\begin{array}{l}\text { LEV (500-1250 } \\
\mathrm{mg} / \text { day) and } \\
\text { placebo in } \\
\text { randomized } \\
\text { sequence, } \\
8 \text { weeks } \\
\text { treatment }\end{array}$ & $\begin{array}{l}9 / 12 \text { improved in treatment group } \\
\text { and } I / / 2 \text { in placebo group. } \\
\text { Significant improvement in tics with } \\
\text { LEV }\end{array}$ & $\begin{array}{l}\text { Discontinuation in I patient } \\
\text { because } \\
\text { of adverse effects }\end{array}$ \\
\hline
\end{tabular}

Abbreviations: Ref, reference list item number; LEV, levetiracetam; ADHD, attention deficit hyperactivity disorder; OCD, obsessive-compulsive disorder.

number, frequency, intensity, complexity, and interference with daily life. Summation of these scores result in a total tic score (TTS). The tic impairment score (TIS) is based on the impact of the tic disorder on self-esteem, family life, social acceptance, and school performance. TIS is added to TTS to obtain the total or global YGTSS score. ${ }^{48}$

The CGI scale is a seven-point, ordinal scale that uses all available information to determine the impact of tics on the subject's quality of life: 1 (healthy), 2 (borderline), 3 (mild), 4 (moderate), 5 (marked), 6 (severe), and 7 (extreme).

Awaad et al ${ }^{49}$ suggested in 2005 that levetiracetam may be a useful treatment for tics. They conducted a prospective, open-label, clinical trial with 60 children and adolescents with tics and previously-untreated TS. Patients were treated with LEV in doses of 1000-2000 mg/day, and no concomitant medications were used. Outcomes were assessed at 1 year with the YGTSS and CGI scales and the Revised Conners
Behavior Scales. The effects on measures of behavior and school performance were also assessed. All patients showed significant clinical improvements in their vocal and motor tics. Also, 43 of the 60 patients showed improvement in their behavior and school performance. Three patients discontinued the treatment because of exacerbation of preexisting behavioral problems.

In a 4-year follow-up of this prospective, open-label study, data were included from 10 additional patients. LEV remained $100 \%$ effective for tic suppression. Improvements were observed within the first 6 weeks of treatment, and persisted over time. Also, $70 \%$ of patients showed improvement in behavior and school performance. ${ }^{50}$

A randomized, placebo-controlled, double-blind, crossover trial ${ }^{51}$ was performed to determine whether LEV could significantly reduce tics in children and adolescents with TS. This study enrolled 22 children aged $8-16$ years old with TS, 
with moderate to moderately severe tics. In a randomized drug sequence, patients received 4 weeks of LEV with a maximum dosage of $30 \mathrm{mg} / \mathrm{kg} /$ day, or placebo, with a 2-week intervening wash-out period between cycles. The primary outcome measures included the total score from the YGTSS and the TTS from the subscale. Measurements were taken at the baseline (before randomization), on day 28 (end of phase I), on day 42 (end of wash-out period and baseline for phase II), and on day 70 (end of phase II). In both placebo and treatment groups, there was a slight reduction in tics compared with baseline measures, but no significant difference was found between groups. The results were not affected by the sequence of treatment. Neither was any difference found in secondary outcome measures for tics (tic impairment score from subscale of YGTSS and CGI scale) nor any effect on attentional symptoms or obsessive-compulsive behaviors.

A randomized, double-blind, flexible-dose, crossover study $^{52}$ compared LEV and clonidine for the treatment of tics in TS patients: 12 subjects with moderate to moderately severe tics were enrolled. Patients received placebo during 1 week to screen for high placebo responders. Subsequently, in a randomized drug sequence, patients received 6 weeks of LEV with a maximum dosage of $50 \mathrm{mg} / \mathrm{kg} /$ day or $2500 \mathrm{mg} /$ day, or clonidine with a 2-week wash-out period between both cycles. Ten patients aged 8-27 years completed the study. Two were withdrawn before the medication phase (one because of important improvement during the placebo run-in phase, and the other as a parental decision). The primary outcome measure was the TTS component of the YGTSS. Secondary outcome measures included the global score of the YGTSS, the CGI scale, and other scales for obsessive-compulsive, attention deficit hyperactivity, depression, and anxiety symptoms. In this study, a small but statistically significant improvement in TTS was fround with clonidine (13\% from baseline). There was no improvement in any tic scores with LEV. Evaluating comorbidities, no significant change in secondary behavioral measures was demonstrated with clonidine or LEV. The most commonly reported side-effect with LEV was irritability, in four patients.

A prospective, open-label study ${ }^{53}$ included 29 patients with TS aged 6-17 years. Patients received LEV with a dosage of approximately $30-40 \mathrm{mg} / \mathrm{kg} /$ day (maximum $2000 \mathrm{mg} /$ day). Concomitant treatment with neuroleptics, clonidine, or methylphenidate was present in more than half of the cases. The authors evaluated the scores from the YGTSS and modified CGI scale at the beginning of the study and at 12 weeks. Twenty-seven patients completed the study. Tics improved in 59\% patients (markedly, in half of them),
$26 \%$ did not reveal significant changes, and tics worsened in $15 \%$ of cases. In the statistical analysis, a significant improvement was observed in TTS and the global score from YGTSS and the CGI scale. When the results of two separate groups (patients with and without associated ADHD) were analyzed, only patients with ADHD-associated diagnosis revealed a significant improvement in TTS and CGI. Most of these patients $(63 \%)$ were treated simultaneously with methylphenidate. Ten cases (37\%) presented adverse effects (most frequently, irritability and drowsiness), which caused discontinuation of treatment in 3 patients (11\%).

A recent prospective, double-blinded, randomized, placebo controlled study ${ }^{54}$ included 24 children aged 6-18 years old with TS and associated diagnoses of epilepsy (14 patients) or headache (10 patients). Children were given LEV (500 to $1250 \mathrm{mg} /$ day) or placebo in a randomized sequence. Twelve patients received LEV: 9 of them showed improvement in tics, 2 were lost to follow-up, and 1 patient with comorbid ADHD and OCD discontinued LEV because of aggressiveness. One patient in the placebo group showed a great placebo effect with improvement in tics, 2 were lost to follow-up, and the remaining nine showed no improvement. Patients receiving LEV showed a significant decrease in frequency, interference, and impairment of motor and vocal tics in YGTSS. Seven patients filled the Conners Parent Rating scale before and after treatment. The 4 patients who improved were in the LEV group.

Other publications are limited to isolated case reports:

- A 23-year-old female with refractory TS whose symptoms improved significantly, when treated with LEV, and persisted at 4-month follow-up. ${ }^{55}$

- A 25-year-old male with severe and refractory TS, who presented an ischemic stroke in association with antiphospholipid syndrome and secondarily epilepsy, was treated with LEV, with improvement in both tic disorder and epileptic syndrome. ${ }^{56}$

\section{Discussion}

New hypotheses and recent studies involving GABAergic system in the pathophysiology of Tourette syndrome propose the starting point for therapeutical trials with GABAergic drugs.

First, trials with the GABAergic drug clonazepam show only a modest effect. Baclofen did not prove to have a clear benefit in suppressing tics in a randomized trial. More recently, topiramate showed a beneficial effect in a randomized trial.

LEV, with an atypical enhancing activity at GABA-A receptors, could be of interest in treatment of tics. Although 
promising results were found in open-label studies, ${ }^{49,50,53}$ and in one randomized study ${ }^{54}$, other controlled trials could not demonstrate a benefit. ${ }^{51,52}$

Several important factors must be taken into account when interpreting the results of therapeutic trials in TS patients, which may explain the contradictory results with LEV.

First, tics have a natural waxing and waning pattern, with marked fluctuations in severity and frequency, and usually improve over time. Even without intervention, a period of severe tics will be followed by one of spontaneous waning. This fluctuating course and variability of symptoms in TS must be considered when interpreting results of clinical studies in these patients.

On the other hand, there is evidence that GABA plays a key role in the pathophysiology of anxiety and stress disorders, and for that reason, LEV has a potential efficacy for the treatment of anxiety. ${ }^{57,58}$ Other studies have suggested a positive effect of LEV on cognitive functioning. In a study with adult patients with partial epilepsy, patients receiving LEV as an add-on therapy had a significant cognitive improvement in attention and oral fluency not related to the seizure frequency, probably due to the effects of LEV itself. ${ }^{59}$ As tics can be exacerbated by factors such as stress, anxiety, and learning difficulties, LEV may indirectly improve tics due to an anxiolytic or cognitive effect.

Also, treatment of comorbidities such as ADHD frequently improve tics in TS patients. ${ }^{16,21}$ In some revised studies, LEV appears to be effective in patients with comorbid ADHD, with improvement in Conners Scale ratings, behavior, and school performance, without concomitant treatments. ${ }^{50,54}$ In another study, LEV significantly reduced tic scores in TS patients with ADHD-associated comorbidity compared to patients without ADHD, most of them treated simultaneously with methylphenidate. ${ }^{53}$ Other studies did not demonstrate an improvement in ADHD or obsessive-compulsive behaviors with LEV. ${ }^{51,52}$

In addition, tics are characterized by suggestibility, and a substantial placebo response has been documented in clinical trials for TS, with large fluctuations in severity scores while receiving placebo. ${ }^{60,61}$

LEV is considered a safe drug with infrequent sideeffects, which include behavioral disorders in children. Although most TS patients treated with LEV had comorbid behavioral problems, this drug was usually well tolerated. The most frequently reported adverse events were headache, somnolence, irritability, and asthenia, while more serious events requiring withdrawal of treatment were unusual (generally exacerbation of previous behavioral disorders such as aggressiveness or impulse behavior disorder).

\section{Conclusions}

LEV is a drug with potential benefits in alleviating tics and neuropsychiatric disorders. Although, at this moment, trials performed to evaluate the efficacy of LEV in the treatment of TS have provided conflicting results, it seems to be useful in some patients. Children and adolescents with associated ADHD may be better candidates for treatment with LEV.

The established safety profile of LEV makes this drug a better-tolerated alternative for treatment if intolerance to currently-used drugs appears. The low risk of drug interactions with LEV might be another consideration for patients who require the concurrent use of other medications for treating comorbid conditions.

The results of some studies, and its safety profile, make LEV an alternative candidate for the treatment of TS. However, additional evaluation with larger, and longerduration, controlled studies are necessary to assess the real efficacy of LEV in TS.

\section{Disclosures}

The authors disclose no conflicts of interest.

\section{References}

1. Mason A, Banerjee S, Eapen V, Zeitlin H, Robertson MM. The prevalence of Tourette syndrome in a mainstream school population. Dev Med Child Neurol. 1998;40:292-296.

2. Kadesjo B, Gillberg C. Tourette's disorder: epidemiology and comorbidity in primary school children. $J$ Am Acad Child Adolesc Psychiatry. 2000;39:548-555.

3. Kurlan R, Como PG, Miller B, et al. The behavioral spectrum of tic disorders: a community-based study. Neurology. 2002;59: 414-420.

4. Freeman RD, Fast DK, Burd L, Kerbeshian J, Robertson MM, Sandor P. An international perspective on Tourette syndrome: selected findings from 3500 individuals in 22 countries. Dev Med Child Neurol. 2000;42:436-447.

5. Berardelli A, Curra A, Fabbrini G, Gilio F, Manfredi M. Pathophysiology of tics and Tourette syndrome. J Neurol. 2003;250:781-787.

6. Swain JE, Scahill L, Lombroso PJ, King RA, Leckman JF. Tourette syndrome and tic disorders:A decade of progress. Am Acad Child Adolesc Psychiatry. 2007;46:947-968.

7. Singer HS, Minzer K. Neurobiology of Tourette's syndrome: concepts of neuroanatomic localization and neurochemical abnormalities. Brain Dev. 2003;25 Suppl 1:S70-S84.

8. Müller-Vahl KR, Kaufmann J, Grosskreutz J, Dengler R, Emrich HM, Peschel T. Prefrontal and anterior cingulate cortex abnormalities in Tourette Syndrome: evidence from voxel-based morphometry and magnetization transfer imaging. BMC Neurosci. 2009;10:47.

9. Singer HS. Tourette's syndrome: from behaviour to biology. Lancet Neurol. 2005;4:149-159.

10. Mink JW. Basal ganglia dysfunction in Tourette syndrome: a new hypothesis. Pediatr Neurol. 2001;25:190-198. 
11. Yoon DY, Gause CD, Leckman JF, Singer HS. Frontal dopaminergic abnormality in Tourette syndrome: a postmortem analysis. J Neurol Sci. 2007;255:50-56.

12. Eapen V, Crncec R. Tourette syndrome in children and adolescents: special considerations. J Psychosom Res. 2009;67:525-532.

13. Leckman JF. Tourette's síndrome. Lancet. 2002;360:1577-1586.

14. Shprecher D, Kurlan R. The management of tics. Mov Disord. 2009;24:15-24.

15. Jankovic J. Treatment of hyperkinetic movement disorders. Lancet Neurol. 2009;8:844-856.

16. Martínez-Granero MA, Montañés F, García-Pérez A, et al. Treatment of Tourette syndrome and its comorbidity: experience with 17 cases. Neurologia. 2005;20:678-685.

17. Pringsheim T, Marras C. Pimozide for tics in Tourette's syndrome. Cochrane Database Syst Rev. 2009;(2):CD006996.

18. Shapiro E, Shapiro AK, Fulop G, et al. Controlled study of haloperidol, pimozide and placebo for the treatment of Gilles de la Tourette's syndrome. Arch Gen Psychiatry. 1989;46:722-730.

19. Silva RR, Muñoz DM, Daniel W, Barickman J, Friedhoff AJ. Causes of haloperidol discontinuation in patients with Tourette's disorder: management and alternatives. J Clin Psychiatry. 1996;57: 129-135.

20. Scahill L, Chappell PB, Kim YS, et al. A placebo-controlled study of guanfacine hydrochloride in the treatment of children with tic disorders and attention deficit hyperactivity disorder. Am J Psychiatry. 2001;158:1067-1074.

21. Bloch MH, Panza KE, Landeros-Weisenberger A, Leckman JF. Metaanalysis: treatment of attention-deficit/hyperactivity disorder in children with comorbid tic disorders. J Am Acad Child Adolesc Psychiatry. 2009;48:884-893.

22. Dion Y, Annable L, Sandor P, Chouinard G. Risperidone in the treatment of Tourette syndrome: a double-blind, placebo-controlled trial. J Clin Psychopharmacol. 2002;22:31-39.

23. Scahill L, Leckman JF, Schultz RT, Katsovich L, Peterson BS. A placebo-controlled trial of risperidone in Tourette syndrome. Neurology. 2003;60:1130-1135.

24. Bruggeman R, van der Linden C, Buitelaar JK, Gericke GS, Hawkridge SM, Temlett JA. Risperidone versus pimozide in Tourette`s disorder: a comparative double-blind parallel-group study. J Clin Psychiatry. 2001;62:50-56.

25. Onofrj M, Paci C, D’Andreamatteo G, Toma L. Olanzapine in severe Gilles de la Tourette syndrome: a 52-week double-blind cross-over study vs low-dose pimozide. J Neurol. 2000;247:443-446.

26. Budman CL, Gayer A, Lesser M, Shi Q, Bruun RD. An open-label study of the treatment efficacy of olanzapine for Tourette's disorder. J Clin Psychiatry. 2001;62:290-294.

27. McConville BJ, Sorter MT. Treatment challenges and safety considerations for antipsychotic use in children and adolescents with psychoses. J Clin Psychiatry. 2004;65 Suppl 6:20-29.

28. De Hert M, Schreurs V, Sweers K, et al. Typical and atypical antipsychotics differentially affect long-term incidence rates of the metabolic syndrome in first-episode patients with schizophrenia: a retrospective chart review. Schizophr Res. 2008;101:295-303.

29. Meyer JM, Koro CE. The effects of antipsychotic therapy on serum lipids: a comprehensive review. Schizophr Res. 2004;70:1-17.

30. Bloch MH. Emerging treatments for Tourette's disorder. Curr Psychiatry Rep. 2008;10:323-330.

31. Kalanithi PSA, Zheng W, KataokaY, et al. Altered parvalbumin-positive neuron distribution in basal ganglia of individuals with Tourette syndrome. Proc Natl Acad Sci U S A. 2005;102:13307-13312.

32. Anderson SA, Eisenstat DD, Shi L, Rubenstein JLR. Interneuron migration from basal forebrain to neocortex: dependence on Dlx genes. Science. 1997;278:474-476.

33. Leckman JF, Walker DE, Cohen DJ. Premonitory urges in Tourette's syndrome. Am J Psychiatry. 1993;150:98-102.
34. Swerdlow NR, Karban B, Ploum Y, Sharp R, Geyer MA, Eastvold A. Tactile prepuff inhibition of startle in children with Tourette's syndrome: in search of an "fMRI-friendly" startle paradigm. Biol Psychiatry. 2001;50:578-585.

35. Ziemann U, Paulus W, Rothenberger A. Decreased motor inhibition in Tourette's disorder: evidence from transcranial magnetic stimulation. Am J Psychiatry. 1997;154:1277-1284.

36. Awaad Y. Tics in Tourette syndrome: new treatment options. J Child Neurol. 1999;14:316-319.

37. Singer HS, Wendlandt J, Krieger M, Giuliano J. Baclofen treatment in Tourette syndrome: A double-blind, placebo-controlled, crossover trial. Neurology. 2001;56:599-604.

38. Jankovic J, Jimenez-Shahed J, Brown LW. A randomized, double-blind, placebo-controlled study of topiramate in the treatment of Tourette syndrome. J Neurol Neurosurg Psychiatry. 2010;81:70-73.

39. Ulloa CM, Towfigh A, Safdieh J. Review of levetiracetam, with a focus on the extended release formulation, as adjuvant therapy in controlling partial-onset seizures. Neuropsychiatr Dis Treat. 2009;5:467-476.

40. Farooq MU, Bhatt A, Majid A, Gupta R, Khasnis A, Kassab MY. Levetiracetam for managing neurologic and psychiatric disorders. Am J Health Syst Pharm. 2009;66:541-561.

41. Poulain P, Margineanu DG. Levetiracetam opposes the action of GABA-A antagonists in hypothalamic neurones. Neuropharmacology. 2002;42:346-352.

42. Rigo JM, Hans G, Nguyen L, et al. The anti-epileptic drug levetiracetam reverses the inhibition by negative allosteric modulators of neuronal GABA- and glycine-gated currents. Br J Pharmacol. 2002;136: 659-672.

43. Noyer M, Gillard M, Matagne A, Hénichart JP, Wülfert E. The novel antiepileptic drug levetiracetam (ucb L059) appears to act via a specific binding site in CNS membranes. Eur J Pharmacol. 1995;286: 137-146.

44. Lynch BA, Lambeng N, Nocka K, et al. The synaptic vesicle protein SV2A is the binding site for the antiepileptic drug levetiracetam. Proc Natl Acad Sci U S A. 2004;101:9861-9866.

45. Crowder KM, Gunther JM, Jones TA, et al. Abnormal neurotransmission in mice lacking synaptic vesicle protein 2A (SV2A). Proc Natl Acad Sci U S A. 1999;96:15268-15273.

46. Cramer JA, De Rue K, Devinsky O, Edrich P, Trimble MR. A systematic review of the behavioral effects of levetiracetam in adults with epilepsy, cognitive disorders, or an anxiety disorder during clinical trials. Epilepsy Behav. 2003;4:124-132.

47. Kossoff EH, Bergey GK, Freeman JM, Vining EP. Levetiracetam psychosis in children with epilepsy. Epilepsia. 2001;42:1611-1613.

48. Leckman JF, Riddle MA, Hardin MT, et al. The Yale Global Tic Severity Scale: Initial testing of a clinician-rated scale of tic severity. J Am Acad Child Adolesc Psychiatry. 1989;28:566-573.

49. Awaad Y, Michon AM, Minarik S. Use of levetiracetam to treat tics in children and adolescents with Tourette syndrome. Mov Disord. 2005;20:714-718.

50. Awaad Y, Michon AM, Minarik S. Long-term use of levetiracetam to treat tics in children and adolescents with Tourette syndrome. J Pediatr Neurol. 2007;5:209-214.

51. Smith-Hicks CL, Bridges DD, Paynter NP, Singer HS. A double blind randomized placebo control trial of levetiracetam in Tourette syndrome. Mov Disord. 2007;22:1764-770.

52. Hedderick EF, Morris CM, Singer HS. Double-blind, crossover study of clonidine and levetiracetam in Tourette syndrome. Pediatr Neurol. 2009; 40:420-425.

53. Fernández-Jaén A, Fernández-Mayoralas DM, Muñoz-Jareño N, Calleja-Pérez B. An open-label, prospective study of levetiracetam in children and adolescents with Tourette syndrome. Eur J Paediatr Neurol. 2009;13:541-545. 
54. Awaad Y, Michon AM, Minarik S, Rizk T. Levetiracetam in Tourette syndrome: a randomized double-blind, placebo-controlled study. J Pediatr Neurol. 2009;7:257-263.

55. Oulis P, Karapoulios E, Masdrakis WG, et al. Levetiracetam in the treatment of antipsychotics-resistant Tourette syndrome. World J Biol Psychiatry. 2007;8:1-2.

56. Seijo-Martínez M, Mosquera-Martínez JA, Romero-Yuste S, CruzMartinez J. Ischemic stroke and epilepsy in a patient with Tourette's syndrome: Association with the antiphospholipid syndrome and good response to levetiracetam. Open Neurol J. 2008;2:32-34.

57. Muralidharan A, Bhagwagar Z. Potential of levetiracetam in mood disorders: a preliminary review. CNS Drugs. 2006;20:969-979.
58. Simon NM, Worthington JJ, Doyle AC, et al. An open-label study of levetiracetam for the treatment of social anxiety disorder. J Clin Psychiatry. 2004;65:1219-1222.

59. Piazzini A, Chifari R, Canevini MP, Turner K, Fontana SP, Canger R. Levetiracetam: an improvement of attention and of oral fluency in patients with partial epilepsy. Epilepsy Res. 2006;68:181-188.

60. Tourette's Syndrome Study Group. Treatment of ADHD in children with tics: a randomized controlled trial. Neurology. 2002;58:527-536.

61. Leckman JF, Hardin MT, Riddle MA, Stevenson J, Ort SI, Cohen DJ. Clonidine treatment of Gilles de la Tourette's syndrome. Arch Gen Psychiatry. 1991;48:324-328.

\section{Publish your work in this journal}

Neuropsychiatric Disease and Treatment is an international, peerreviewed journal of clinical therapeutics and pharmacology focusing on concise rapid reporting of clinical or pre-clinical studies on a range of neuropsychiatric and neurological disorders. This journal is indexed on PubMed Central, the 'PsycINFO' database and CAS, and is the official journal of The International Neuropsychiatric Association (INA). The manuscript management system is completely online and includes a very quick and fair peer-review system, which is all easy to use. Visit http://www.dovepress.com/testimonials.php to read real quotes from published authors.

\footnotetext{
Submit your manuscript here: http://www.dovepress.com/neuropsychiatric-disease-and-treatment-journal
} 